\title{
AN ANTHROPOMETRIC STUDY OF NASAL INDEX WITH ITS CLINICAL CORRELATION
}

\section{Maitreyee M. Kulkarni ${ }^{1}$, Jagdish S.Soni ${ }^{2}$, Shital Bhishma Hathila ${ }^{* 3}$.}

${ }^{1}$ M.Sc Medical Anatomy Part II, Medical College Baroda, Gujarat, India.

${ }^{2}$ Associate Professor, Anatomy Department, Medical College, Baroda, Gujarat, India.

${ }^{* 3}$ Assistant Professor, Anatomy Department, Medical College, Baroda, Gujarat, India.

\section{ABSTRACT}

Background: Nose is an important anatomical and physiological part of face. Its anatomy considerably affects its function of inhalation and temperature regulation of inspired air. The anatomy is affected by genetic, racial as well as geographical factors. The aim of the study was to measure nasal height and width in the population being studied so as to calculate nasal index and classify noses on the basis of calculated index.

Materials and method: The study was conducted on 159 healthy volunteers aged 18-25 years in Medical College Baroda, Gujarat. Nasal height and Nasal width were measured by digital vernier caliper and the nasal index was calculated. The type of nose was determined on the basis of the nasal index.

Results: In the present study the mean nasal index is found to be $73.28 \pm 10$. Mean nasal index is observed as $106.46 \pm 6.24$ in males \& $71.94 \pm 8.02$ in females. The $t$ test value calculated is 26.725 at $\mathrm{Cl} 95 \%$ with $\mathrm{P}<0.0001$ showing highly significant difference in nasal indices of male and female. Mesorrhine is the commonest nasal type found.

Conclusion: The study will be highly useful to plastic surgeons, craniofacial surgeons, otolaryngologists, anatomists, forensic experts, orthodontists and medical illustrators alike.

KEY WORDS: Anthropometry, Nasal Height, Nasal width, Nasal Index, Mesorrhine

Address for Correspondence: Dr.Shital. Bhishma. Hathila, A-13,Darshanam Villa-2, Near Sapphire School, Near Savita Hospital, Parivar Cross Road, WaghodiaRoad, Baroda,Gujarat-390025, India. Mobile: 9825121336 E-Mail: bhishushital@gmail.com

Access this Article online

Quick Response code

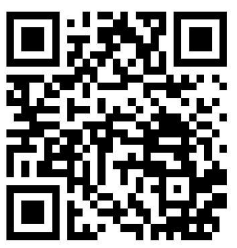

DOI: $10.16965 /$ ijar.2019.121

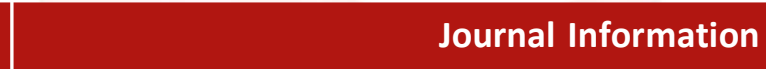

International Journal of Anatomy and Research

ICV for 2016 ISSN (E) 2321-4287 | ISSN (P) 2321-8967

https://www.ijmhr.org/ijar.htm

DOI-Prefix: https://dx.doi.org/10.16965/ijar

Article Information

Received: 24 Jan 2019

Peer Review: 25 Jan 2019

Revised: None
Accepted: 07 Mar 2019

Published (O): 05 Apr 2019

Published (P): 05 Apr 2019

\section{INTRODUCTION}

The word Anthropometry is a combination of two Greek words "anthropos" meaning man and the "metron" meaning to measure and thus is the measurement of human being [1]. Time and again various scientists have emphasized the importance of physical anthropometry in plastic surgeries involving head and neck, orthodontics and forensics for the recognition of missing or dead people and criminals [1]. Nasal parameters especially the shape and size become crucial as the nose occupies a central position in facial architecture [2]. The nasal index is an important anatomical tool that can be used to figure out sexual, racial and ethnic differences. Nasal index is a ratio of nasal width to nasal height multiplied by 100 that helps in the classifying noses into different types [3]. The noses also reflect the trends of natural selection in evolution as it is observed that in cold and dry climates generally favor narrow noses whereas broader noses are seen in warm and 
moist climates [4]. Nasal index finds its use in surgeries like rhinoplasty and other cosmetic surgeries, being the primary step in proceeding for surgery [5].

\section{MATERIALS AND METHODS}

The present study was conducted after taking permission from the Institutional Ethical Committee for Human Research (IECHR) of Medical College Baroda, Gujarat, on 159 healthy volunteers aged between 18-25 years. Volunteers having any existing or past craniofacial trauma or deformities such as cleft lip, cleft palate, or having undergone facial or nasal surgeries, were excluded from the study. Consent of the volunteers was taken after explaining them the process of measurement. Measurements were obtained with volunteers sitting comfortably with head in Frankfurt's plane [6].

Frankfurt's plane is defined as Line connecting the lowest point infraorbital margin i.e. orbitale to upper edge of external acoustic meatus i.e porion $[7,8]$.

Following parameters are calculated for the measurement of nasal index:

Nasal Height i.e. the distance between nasion (n) and subnasale (sn) where nasion is the midpoint of the nasofrontal suture and subnasale is the junction between the lower border of the nasal septum and the cutaneous portion of the upper lip [6,9]

Nasal width i.e. the distance between alae of nose bilaterally [6].

Nasal index is Nasal width divided by Nasal Height multiplied by 100 [6].

According to nasal index, noses were categorized as follows [6]

- Leptorrhine $<70$

- Mesorrhine 70-84.9

- Platyrrhine $>85.4$

All the data was measured using digital vernier calliper (sensitivity: $0.1 \mathrm{~mm}$ ) in millimetres; documented, analysed with Microsoft excel \& presented as mean,standard deviation, range and percentage distribution. t-test was applied and the results with $p<0.05$ were considered significant [6].
Fig. 1: Measurement Of Nasal Height.

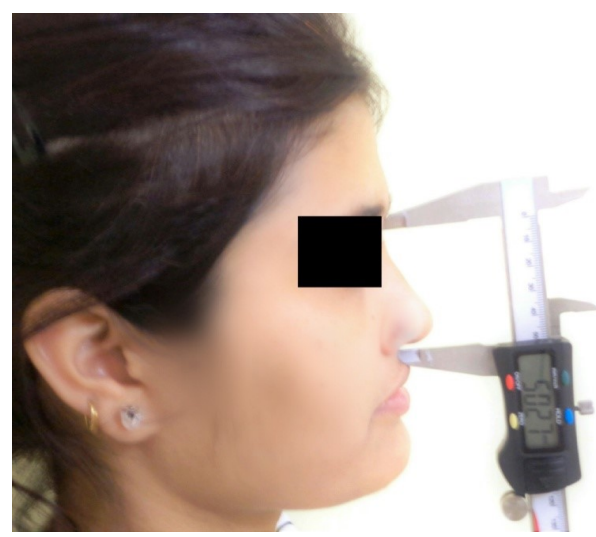

Fig. 2: Measurement Of Nasal Width.

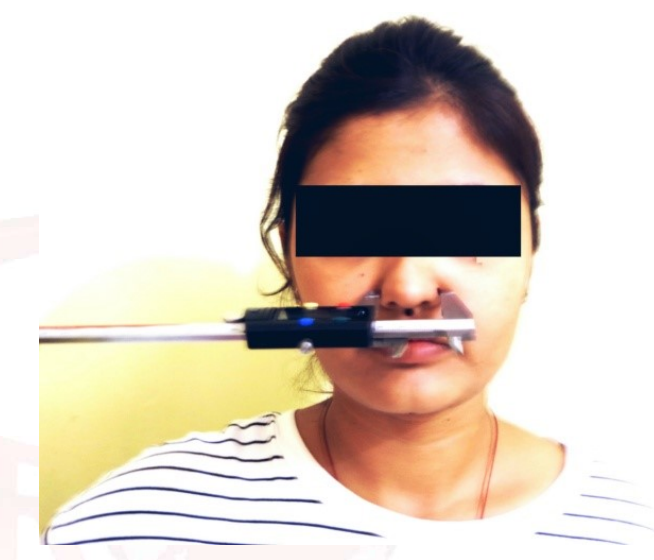

\section{OBSERVATIONS AND RESULTS}

The mean nasal height and nasal width for all the subjects was found to be $42.17 \pm 4.1 \mathrm{~mm}$ and $30.75- \pm 3.23 \mathrm{~mm}$. The mean nasal index is $73.28 \pm 10$. The range is observed to be 139.64 $51.86 \mathrm{~mm}$ [table1].

The commonest nasal type is mesorrhine $58.4 \%$ followed by leptorrhine $30.8 \%$ and platyrrhine $10.6 \%$ [table2, graph1].

Mean nasal height observed in males and females was $43.99 \pm 4.95 \mathrm{~mm}$ and $41.43 \pm 3.45 \mathrm{~mm}$ respectively [table 3 ]

Mean Nasal width observed was $32.91 \pm 3.15 \mathrm{~mm}$ in males and $29.65 \pm 2.73 \mathrm{~mm}$ in females [table3].

Mean Nasal index is $106.46 \pm 6.24$ in males \& $71.94 \pm 8.02$ in females. The range observed in males is $139.64-51.86 \mathrm{~mm}$ and in females is $100.23-52.30 \mathrm{~mm}$ [table 3]. The $t$ test value is 26.725 at $\mathrm{Cl} 95 \%$ with $\mathrm{P}<0.0001$ showing highly significant difference in nasal indices of male and female [table 3].

In this study the major nose type is mesorrhinic in both males and females being $79.59 \%$ and $56.36 \%$ respectively. Mesorrhinic type is 
followed by leptorrhinic (males: $22.45 \%$; females: $34.55 \%$ ) and Platyrrhinic ( males: 16.33\%; females: 9.09\%) [table 4, graph 2]

Table 1: Parameters In The Studied Population.

\begin{tabular}{|c|c|c|c|}
\hline & $\begin{array}{c}\text { Nasal Height } \\
(\mathrm{mm})\end{array}$ & $\begin{array}{c}\text { Nasal Width } \\
(\mathrm{mm})\end{array}$ & Nasal Index \\
\hline Mean & 42.17 & 30.75 & 73.28 \\
\hline SD & 4.1 & 3.23 & 10 \\
\hline Range & $52.83-22.98$ & $39.75-22.36$ & $139.64-51.86$ \\
\hline
\end{tabular}

Table 2: Percentage Distribution Of Nasal Types.

\begin{tabular}{|c|c|}
\hline Type & Percentage (\%) \\
\hline Leptorrhine & 30.8 \\
\hline Mesorrhine & 58.4 \\
\hline Platyrrhine & 10.6 \\
\hline
\end{tabular}

Table 3: Parameters in Male and Female.

\begin{tabular}{|c|c|c|c|c|c|c|}
\hline \multirow{2}{*}{ Sex } & \multicolumn{2}{|c|}{ Nasal Height $(\mathrm{mm})$} & \multicolumn{2}{c|}{ Nasal Width(mm) } & \multicolumn{2}{c|}{ Nasal Index } \\
\cline { 2 - 7 } & Mean & Range & Mean & Range & Mean+\$D & Range \\
\hline Male & 43.99 & $52.83-22.98$ & 32.91 & $39.75-26.9$ & $106.46+6.24$ & $51.86-139.64$ \\
\hline Female & 41.43 & $49.62-31.34$ & 29.65 & $38.68-22.36$ & $71.94- \pm 8.02$ & $100.23-52.30$ \\
\hline t value & \multicolumn{2}{|c|}{26.725} & \multicolumn{4}{|c|}{ P<0.0001 } \\
\hline
\end{tabular}

Table 4: Percentage Distribution of Nasal Types In Males And Females.

\begin{tabular}{|c|c|c|}
\hline Nasal Type & Female (\%) & Male (\%) \\
\hline Leptorrhine & 34.55 & 22.45 \\
\hline Mesorrhine & 56.36 & 79.59 \\
\hline Platyrrhine & 9.09 & 16.33 \\
\hline
\end{tabular}

Table 5: Comparison Of The Current Study With Other Studies.

\begin{tabular}{|c|c|c|c|}
\hline Study & Sex & Nasal Index & $\begin{array}{c}\text { Predominant } \\
\text { Nasal Type }\end{array}$ \\
\hline \multirow{2}{*}{ Present Study } & $\mathbf{M}$ & $106.46 \pm 6.24$ & \multirow{2}{*}{ Mesorrhine } \\
\cline { 2 - 3 } & $\mathbf{F}$ & $71.94 \pm 8.02$ & \\
\hline \multirow{2}{*}{ Ukoha et al [3] } & $\mathbf{M}$ & $89.95 \pm 11.26$ & \multirow{2}{*}{ Not Observed } \\
\cline { 2 - 3 } & $\mathrm{F}$ & $85.71 \pm 10.76$ & \\
\hline \multirow{2}{*}{ Ray et al [6] } & $\mathbf{M}$ & $75.86 \pm 7.6$ & \multirow{2}{*}{ Mesorrhine } \\
\cline { 2 - 4 } & $\mathrm{F}$ & $72.08 \pm 7.39$ & \\
\hline \multirow{2}{*}{ Patil et al [4] } & $\mathbf{M}$ & 84.91 & Mesorrhine \\
\cline { 2 - 3 } & $\mathrm{F}$ & 67.75 & Leptorrhine \\
\hline Chettri et al [10] & $\mathbf{F}$ & $70.7 \pm 18.35$ & Leptorrhine \\
\hline
\end{tabular}

Graph 1: Percentage Distribution Of Nasal Types.

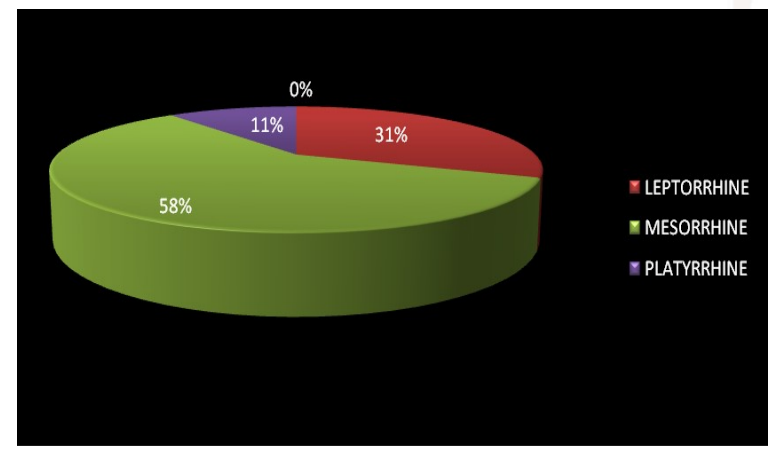

Graph 2: Percentage Distributions Of Nasal Types In Males And Females.

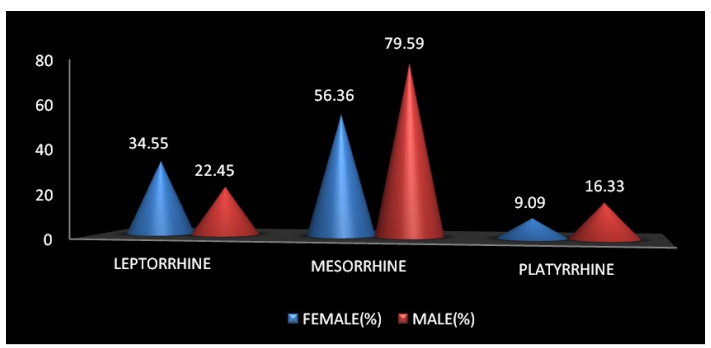

\section{DISCUSSION}

The morphometric variations in the nasal measurements globally have become the centre of investigation for cosmetic and plastic surgeons, responsible for repair and reconstruction of the nose [10]. The nose is often regarded as one of the useful indicators to race of the individual. The diverse shapes of the nose are mainly influenced through the environment and temperatures. The cold and dry climate favor narrower noses. On the other hand, broad and wide noses are a feature of warm regions [5]. Different authors, namely Dr.M.N.Chettri et al (2017)[10], Ray et al(2016) [6], Ukoha et al (2016) [3], Ashrani et al(2015) [5] and many more have enormously contributed to the subject matter.

In the present study the mean nasal index is found to be $73.28 \pm 10$ which is comparable to the study conducted by Ray et al who also observed the mean nasal index to be $73.98 \pm 1.9$ [6].

The current study also observes that the mean nasal index among males is $106.46 \pm 6.24$ that significantly differs from females being $71.94 \pm 8.02$. Such wide differences are also reported by Patil et al who observed mean Nasal index among males to be 84.91and in females to be 64.75 [4]. On the contrary the mean nasal indices among male and female are observed to be similar by Ukoha et al $89.95 \pm 11.26$ and $85.71 \pm 10.76$ respectively [3].

They are also alike in case of Ray et al [6] who reports them to be $75.86 \pm 7.6$ and $72.08 \pm 7.39$ respectively [table 5 ].

The most frequent nasal type in the current study is found to be mesorrhinic type in both males and females. This is comparable to Ray et al who also observed mesorrhinic type to be the commonest among population of western Uttar 
Pradesh [6]. Chettri et al [10] who studied the female students in Sikkim University reported leptorrhine type as the most frequent finding. Patil et al [4] observes mesorrhine type being the commonest in males and leptorrhine type in females in south India which differs from the results of current study.

Anju Choudhary et al compared the mean nasal height for Jats and Sindhis and reported them to be $56.42 \pm 3.70 \mathrm{~mm}$ \& $55.84 \pm 4.61 \mathrm{~mm}$ respectively. They also inferred that the predominant nasal type among Jats was Leptorrhine and among Sindhis was Mesorrhine [11].

Hegazy AA et al observed Nasal index showed only after the age of 20 years statistically significant difference is observed between males and females. Hegazy et al observed the age wise trend from 1 month to 65 years in healthy Egyptians. At one year the mean Nasal index above 85 , classified as platyrrhine nose. It declined after first to fifth year to be 70 and type of nose was mesorrhine. Above twenty years, statistically significant difference is seen among males and females; the mean nasal index being 71.46 in males and 64.56 in females [9].

The study by Asharani S K et al pointed that the Indian population mainly has mesorrhine type of nose followed by platyrrhine and leptorrhine types [5].

\section{CONCLUSION}

The multitude of factors influences size, shape, and length of the nose such as genetics, sex, racial origins and environmental conditions [3]. Our study indicates the significant difference among the nasal indices in males and females. The index relies on both bony and cartilaginous anatomical surface points. The natural selection according to climatic conditions aids in augmenting the efficiency of the nose keeping the inhaled air warm and moist as required for the individual [10].

This study is vital in medical sciences such as cosmetology and rhinoplasty and will also help orthodontists, facio-maxillary surgeons, anatomists and anthropologists alike [12]. Such anthropometric data will also facilitate manufacture of better medical gear and tools[1].

\section{ABBREVIATIONS}

mm-Millimeters

$\mathrm{Cl}$ - Confidence Interval

M- Male

F- Female

Conflicts of Interests: None

\section{REFERENCES}

[1]. Ranjana G, Rohini M, Manik C. Anthropometric Assessment Of Morphological Facial Index Of Gond Males And Females Of Uttar Bastar Kanker, C.G. Int J Anat Res 2016;4(4):3170-3174. DOI: 10.16965/ ijar.2016.431

[2]. Uzun A, Ozdemir F Morphometric analysis of nasal shapes And angles in young adults. Braz J Otorhinolaryngol.2014; 80:397-402.

[3]. Ukoha UU, Egwu OA, Ndukwe GU, Akudu LS, Umeasalugo KE. Anthropometric study of the nose in a student population. Ann Bioanthropol 2016;4:811.

[4]. Dr. Girish V. Patil et al, Study on nasal index in south Indian population. International Journal of Current Research 2014;6(8):8163-8164.

[5]. Asharani S K, Tejaswi Hiremarali Lokanathan, Rajendra R, Surendra M. Study Of Nasal Index Among Students Of Tertiary Medical Care Institute In Southern India. Int J Anat Res 2015; 3(4):1675-1679. DOI: 10.16965/ijar.2015.314

[6]. Ray SK, Saha K, Kumar A, Banjare S. Anthropometric Study of Nasal Index among the Population of Western Uttar Pradesh Region. Int J Sci Stud 2016;4(2):6570.

[7]. Dutta A.K., Essentials of Human Anatomy. Head \& Neck: Current Books International; 2017.

[8]. Wilder H, A Laboratory Manual of Anthropo metry.Philadelphia P. Blakiston's Son \& Co; 1920.

[9]. Hegazy A A. Anthropometric Study of Nasal Index of Egyptians. Int J Anat Res 2014;2(4):761-767. DOI: 10.16965/ijar.2014.544

[10]. Chettri M.N, Sinha P Naso-Facial Anthropometric Study of Female Sikkimese University Students. IOSR Journal of Dental and Medical Sciences 2017; 16 (3) 49-54.

[11]. Choudhary Anju, Chowdhary DS, Comparative Anthropometric Study of Nasal Parameters between Two Ethnic Groups of Rajasthan State. [Int. J. Med. Public health 2012.2(2);46-48.

[12]. Kataria DS, Ranjan RK, Perwaiz SA. Study of variation in total facial index of north Indian population. Int J Health Sci Res. 2015; 5(4):122-127.

How to cite this article: Maitreyee M. Kulkarni, Jagdish S.Soni, Shital Bhishma Hathila. AN ANTHROPOMETRIC STUDY OF NASAL INDEX WITH ITS CLINICAL CORRELATION. Int J Anat Res 2019;7(2.1):6377-6380. DOI: 10.16965/ijar.2019.121 